\title{
COMPROMETIMENTO, BEM-ESTAR E SATISFAÇÃO DOS PROFESSORES DE ADMINISTRAÇÃO DE UMA UNIVERSIDADE FEDERAL
}

\author{
Maria Teodora Farias Traldi \\ teodoratraldi@hotmail.com \\ Universidade de Brasília - Brasília, DF/Brasil \\ Gisela Demo \\ giselademo@gmail.com \\ Universidade de Brasília - Brasília, DF/Brasil
}

\begin{abstract}
Recebido em 01/08/2010
Aprovado em 29/08/2011

Disponibilizado em 01/08/2012

Avaliado pelo sistema double blind review

Revista Eletrônica de Administração

Editor: Luís Felipe Nascimento

ISSN 1413-2311 (versão on-line)

Editada pela Escola de Administração da Universidade Federal do Rio Grande do Sul.

Periodicidade: Quadrimestral
\end{abstract}

Sistema requerido: Adobe Acrobat Reader.

\section{RESUMO}

As pesquisas sobre o comprometimento organizacional, o bem-estar e a satisfação no trabalho vêm sendo realizadas com êxito na área de Psicologia Organizacional. Novos estudos sinalizam uma possível interdependência entre estes construtos. $\mathrm{O}$ objetivo precípuo desta pesquisa foi investigar as relações entre comprometimento organizacional, bem-estar e satisfação no trabalho, através de um censo realizado com os 104 professores de Administração de uma Universidade Federal, com taxa de resposta de $78 \%$. Trata-se de uma pesquisa de campo, explicativa-descritiva, possuindo caráter transversal e natureza quantitativa. Os resultados mostraram que os professores apresentaram bons níveis de realização no trabalho e afetos positivos prevalentes em relação aos afetos negativos; declararam-se satisfeitos no trabalho quanto à chefia, aos colegas e à natureza do trabalho. $\mathrm{O}$ comprometimento organizacional normativo foi o único que contribuiu para a explicação da satisfação com o salário. O comprometimento organizacional calculativo contribuiu para a explicação dos fatores satisfação com a chefia e satisfação com as promoções. Finalmente, o comprometimento organizacional afetivo foi o principal preditor do bem-estar e da satisfação no trabalho. Este trabalho contribuiu tanto para a produção acadêmica das áreas de Psicologia e Comportamento Organizacional, quanto para a tomada de decisão quanto às políticas de gestão dos professores pesquisados, na perspectiva de que docentes e discentes possam desfrutar de um melhor ambiente de aprendizagem e produção do conhecimento.

Palavras-chave: Comprometimento organizacional, bem-estar no trabalho, satisfação no trabalho, professores de Administração, Universidade Federal.

REAd I Porto Alegre - Edição 72 - Nº 2 - maio/agosto 2012 - p. 290-316 


\title{
COMMITMENT, WELL-BEING AND SATISFACTION OF MANAGEMENT PROFESSORS AT A FEDERAL UNIVERSITY
}

\begin{abstract}
Research on organizational commitment, well-being and job satisfaction have been performed successfully in the field of Organizational Psychology. New studies indicate a possible interdependence between these constructs. The main objective of this research was to investigate the relationships between organizational commitment, well-being and job satisfaction, through a census conducted with 104 professors of Management at a Federal University, with a response rate of $78 \%$. This survey consists of an explanatory-descriptive study, having transversal and quantitative nature. The results showed that teachers had good levels of achievement at work and positive affect predominant over negative affect; they also expressed their satisfaction at work on the bosses, colleagues and the nature of work. The normative organizational commitment was the only one who contributed to the explanation of satisfaction with salary. The calculative organizational commitment has contributed to the explanation of the factors leading to satisfaction and satisfaction with the promotions. Finally, affective organizational commitment was the main predictor of well-being and job satisfaction. This work contributed to both the academic field of Organizational Behavior, as for decision making regarding the management policies of the professors surveyed, with the expectation that both professors and students can enjoy a better environment for learning and knowledge production.
\end{abstract}

Keywords: organizational commitment, well-being at work, satisfaction at work, Management professors, Federal University.

\section{COMPROMETIMIENTO ORGANIZACIONAL, BIEN ESTAR Y SATISFACCIÓN EN EL TRABAJO DE LOS PROFESORES DE ADMINISTRACIÓN DE UNA UNIVERSIDAD FEDERAL}

\begin{abstract}
RESUMEN
Las investigaciones sobre el comprometimiento organizacional, el bien estar y la satisfacción en el trabajo continúan a realizarse con éxito en el área de la Psicología Organizacional. Nuevos estudios señalan una posible interdependencia entre estos constructos. El objetivo mayor de esta investigación fue estudiar las relaciones entre comprometimiento organizacional, bien estar y satisfacción en el trabajo, por medio de un censo realizado con los 104 profesores de Administración de una Universidad Federal, con índice de respuestas de $78 \%$. Se trata de una investigación de campo, explicativa-descriptiva, poseyendo carácter transversal y naturaleza cuantitativa. Los resultados mostraran que los profesores presentaran buenos niveles de realización en el trabajo e afectos positivos prevalentes en relación a los afectos negativos; se declararan satisfechos en el trabajo cuanto a los jefes, a los colegas e a la naturaleza del trabajo. El comprometimiento organizacional normativo fue el único que contribuyó para la explicación de la satisfacción con el salario. El comprometimiento organizacional calculativo contribuyó para la explicación de los factores satisfacción con los jefes y satisfacción con las promociones. Finalmente, el comprometimiento organizacional afectivo fue el principal predictor del bien estar e de la satisfacción en el trabajo. Este trabajo
\end{abstract}

REAd I Porto Alegre - Edição 72 - N 2 - maio/agosto 2012 - p. 290-316 
Comprometimento, bem-estar e satisfação dos professores de administração de uma universidade federal

contribuyó tanto para la producción académica de las áreas de Psicología y Comportamiento Organizacional, cuanto para la domada de decisión frente a las políticas de gestión de los profesores investigados, en la perspectiva de que docentes y discentes puedan desfrutar de un ambiente mejor de aprendizaje y producción de conocimiento.

Palabras clave: comprometimiento organizacional, bien estar en el trabajo, satisfacción en el trabajo, profesores de Administración, Universidad Federal.

\section{INTRODUÇÃO}

Uma quantidade expressiva de estudos, como o de Siqueira e Gomide Junior (2004), vem sendo realizada com o objetivo de desvendar cada vez mais a natureza e as peculiaridades das relações existentes no ambiente de trabalho, seja a relação colaborador-organização, seja o significado e o impacto da atividade laboral na vida do colaborador. Conforme apontado por Siqueira (2008), novos estudos sinalizam uma possível interdependência entre comprometimento, satisfação e bem-estar no trabalho.

Considerando-se, ainda, que os últimos editais para contratação de professores de universidades públicas vêm exigindo cada vez mais um regime de dedicação exclusiva, é importante que os profissionais nesse regime estejam comprometidos com seu trabalho. $\mathrm{Na}$ mesma linha, Rego (2002) presume que as pessoas mais comprometidas têm maiores probabilidades de permanecerem na organização e de se empenharem na consecução do seu trabalho e dos objetivos organizacionais. Diversos autores também concordam que o comprometimento pode ter implicações no absenteísmo, na rotatividade, em comportamentos de cidadania, na satisfação, no desempenho das pessoas e na própria eficácia das organizações (MEYER, 1997; GOLEMAN, 1996; MACKENZIE, PODSAKOFF e AHEARNE, 1998; COHEN, 2000).

Ademais, conforme Rego (2002), é pertinente e contributivo abordar o comprometimento de professores universitários, como já feito em outros estudos ( porque a fertilidade dos estudos em meios organizacionais convencionais não tem correspondência direta com as pesquisas realizadas com docentes do ensino superior.

Nesse contexto, propõe-se a pergunta: o comprometimento com a universidade pode influenciar a satisfação e o bem-estar dos professores? Por conseguinte, o objetivo principal desta pesquisa foi avaliar a influência do comprometimento organizacional dos professores que lecionam disciplinas para alunos do curso de Administração na universidade pesquisada em seu bem-estar e satisfação, verificando os preditores destes construtos a partir dos modelos REAd I Porto Alegre - Edição 72 - N 2 - maio/agosto 2012 - p. 290-316 
propostos. Buscou-se identificar, também, os níveis de comprometimento, bem-estar e satisfação dos professores pesquisados.

Para consecução dos objetivos propostos, será enunciado, em primeira instância, o referencial teórico do trabalho, visitando os estudos sobre comprometimento organizacional, bem-estar no trabalho e satisfação no trabalho. Em seguida, será apresentado o método, englobando os modelos de pesquisa, a caracterização da pesquisa, da amostra e dos instrumentos utilizados e, por fim, os procedimentos de coleta e análise dos dados. Seguem-se os resultados engendrados e sua discussão que, por sua vez, fomentarão as conclusões da pesquisa, mormente no que tange às suas contribuições e às recomendações para estudos futuros.

\section{REFERENCIAL TEÓRICO}

Esta seção apresenta uma breve fundamentação teórica do trabalho, resultado da revisão de literatura das variáveis relevantes à consecução da pesquisa.

\subsection{Comprometimento organizacional}

O vínculo do colaborador e da empresa já vem sendo estudado desde o século $\mathrm{XX}$, despertando um interesse maior com o início do processo de globalização. Tenbrunsel e outros (2002) ressaltam que o comprometimento no trabalho é oriundo da categoria contratos psicológicos entre organização e empregados, dentro da disciplina do comportamento organizacional. Estes autores trabalham o construto como um conceito atitudinal, em função de ser uma variável interveniente ou um elo não observável entre estímulos observáveis e uma resposta observável, incluindo tendências cognitivas e comportamentais.

Medeiros e outros (2003) acrescentam que o século XX mostrou diversas pesquisas abordando o comprometimento como um construto multidimensional, de modo a entender os indivíduos e seus complexos vínculos com a organização. Não obstante, Demo (2003, p. 190) ressalta que os estudos sobre comprometimento "têm se concentrado no foco organizacional e na base afetiva, tanto no Brasil quanto no exterior". A autora sustenta ainda que o vínculo do comprometimento organizacional pode ser baseado em múltiplos processos psicológicos, além de poder ser estudado sob múltiplos focos, tais quais, com a organização, com a carreira e com o sindicato.

REAd I Porto Alegre - Edição 72 - N 2 - maio/agosto 2012 - p. 290-316 
Comprometimento, bem-estar e satisfação dos professores de administração de uma universidade federal

Quanto às bases do comprometimento, Bastos (1998) as enumera, a saber, afetiva/atitudinal (processo de identificação do indivíduo com os objetivos e valores da organização); instrumental/calculativa/de continuação (produto das recompensas e custos percebidos pelo empregado na condição de integrante da organização); sociológica (vínculo que surge das relações de autoridade com o empregador); normativa (conjunto de pressões de normas sociais que definem o vínculo do empregado com a empresa) e comportamental (tal conceito existe em relação a um conjunto de cognições que guiam os comportamentos que fortalecem o vínculo com a organização, como, por exemplo, chegar pontualmente ao trabalho). Essas diferentes bases têm conduzido a tipologias de comprometimento, como mostram os trabalhos de Meyer, Allen e Smith (1993), que apresentam um modelo tridimensional de comprometimento: afetivo, de continuação (ou calculativo ou instrumental) e normativo.

No presente estudo, utilizou-se o foco organizacional do comprometimento, contemplando as três bases mais estudadas, a saber, afetiva, calculativa e normativa.

Allen e Meyer (1990) caracterizaram as bases do comprometimento organizacional. Empregados com forte comprometimento afetivo permanecem na organização porque desejam fazê-lo; aqueles com comprometimento calculativo permanecem porque precisam e aqueles com comprometimento normativo permanecem porque sentem que são obrigados.

Para Mowday, Porter e Steers (1982), o comprometimento afetivo pode ser definido pelas suas principais características, a saber: crença e aceitação dos objetivos e valores organizacionais; disposição para defender a organização; e desejo de manter o vínculo com ela. Para os autores, este tipo de comprometimento vai além da simples lealdade passiva à organização, perfazendo uma relação ativa onde o colaborador deseja dar algo de si a fim de contribuir para o bem-estar da organização em que trabalha.

Segundo Siqueira e Gomide Júnior (2004), enquanto o comprometimento afetivo contempla as ligações afetivas com a organização e insere-se no âmbito da afetividade, tanto o comprometimento calculativo quanto o normativo representam dimensões cognitivas particulares da relação entre colaborador e organização.

Siqueira (2000) sugere que o comprometimento calculativo pode ser vislumbrado pelo ato do colaborador permanecer na organização a partir da motivação de percepções individuais sobre custos/perdas de investimento decorrentes do desligamento da organização. Ou seja, a organização contará com o colaborador enquanto ela for atraente para ele. A 
mesma autora afirma que as crenças do colaborador sobre a dívida social para com a organização, ou a necessidade de retribuir um favor integram o comprometimento organizacional normativo.

Dessa forma, os colaboradores que possuem alto nível de comprometimento normativo se sentem presos à organização que, por sua vez, possui diferentes formas de fazer com que seus colaboradores se sintam incapazes de abandoná-la. Nessas organizações, existe grande contato entre organização e colaboradores de modo semelhante a uma família com regras de conduta e missão muito fortes, de modo a levar o colaborador à convicção de que a organização necessita dele para continuar obtendo sucesso. Em outras palavras, os colaboradores que são comprometidos normativamente continuam trabalhando para a organização por um sentimento de dívida ou ainda, obrigação. Portanto, se o colaborador permanece na organização porque se sente moralmente vinculado a ela ou aos colegas, verifica-se a presença do comprometimento normativo.

A produção nacional recente sobre comprometimento no trabalho é vigorosa, com crescente interesse dos pesquisadores sobre o tema. O comprometimento organizacional tem sido investigado em diversos setores de atividades como educacional, portuário, hospitalar, agroindustrial, bancário e tecnológico. Contudo, o principal foco dos estudos é o organizacional e a principal base investigada é a afetiva. Observou-se, também, uma presença massiva de estudos quantitativos como os que relacionaram o comprometimento à espiritualidade nas organizações (REGO, CUNHA, SOUTO, 2007), aos vínculos empregatícios e à qualidade de vida no trabalho (SCHIRRMEISTER e outros, 2008), à justiça organizacional (RIBEIRO, 2008) e à geração de vantagem competitiva sustentável (JÚNIOR e outros, 2007).

Em suma, apesar da aparente consolidação dos estudos sobre o tema, sugere-se a realização de trabalhos de desenvolvimento teórico, pesquisas no terceiro setor, investigações que integrem as múltiplas bases e focos do comprometimento e uma combinação de diferentes perspectivas metodológicas para melhor se compreender o construto.

\subsection{Bem-estar no trabalho}

Mäkikangas e Kinnunem (2003) ressaltam que os colaboradores têm passado por significativas mudanças laborais, aumentando seu nível de estresse no trabalho e refletindo prejudicialmente no nível de bem-estar. Dessa forma, cada vez mais os profissionais da REAd I Porto Alegre - Edição 72 - Nº 2 - maio/agosto 2012 - p. 290-316 
Comprometimento, bem-estar e satisfação dos professores de administração de uma universidade federal

Administração por meio de estudos realizados pela Psicologia vêm se conscientizando da importância do bem-estar no trabalho e de seus reflexos na produtividade, no clima organizacional e nos demais resultados. A tendência dos pesquisadores tem sido identificar a relação entre as emoções vivenciadas pelo colaborador em decorrência do trabalho e como estas afetam a saúde e o desempenho dos profissionais.

Diener (2000) relata que os estudos a respeito do bem-estar surgiram no início dos anos sessenta e que tal temática vem recebendo um crescente interesse. Outras denominações também identificam este construto, tais como felicidade, afetos positivos e avaliação subjetiva da qualidade de vida. No presente estudo, adotou-se a denominação bem-estar no trabalho. Para Albuquerque e Tróccoli (2004), o estudo do bem-estar refere-se à produção acadêmica de investigações acerca da felicidade. No que tange ao bem-estar geral, pode-se dividi-lo em duas correntes: a do bem-estar subjetivo e a do bem-estar psicológico, sendo a principal diferença a concepção de felicidade adotada.

A concepção de felicidade a partir do bem-estar subjetivo tem origem na tradição hedônica. A proposta dos autores que se filiam à concepção hedônica de felicidade é que o bem-estar engloba a experiência de prazer e desprazer, ocasionando assim, julgamentos relativos aos elementos positivos e negativos da vida. Nessa linha, Albuquerque e Tróccoli (2004) veem o bem-estar subjetivo a partir de três dimensões, a saber, o afeto positivo, o afeto negativo e a satisfação com a vida. Além disso, os autores alertam para o fato de que apresentar um alto nível de bem-estar não significa necessariamente a ausência de emoções negativas, mas apenas o predomínio de emoções positivas sobre as negativas. A satisfação com a vida consiste em um julgamento cognitivo da própria vida e inclui as circunstâncias da vida da pessoa e os padrões escolhidos por ela. Portanto, o bem-estar subjetivo é a ocorrência de frequentes afetos positivos, rara experiência emocional negativa e a satisfação com a vida como um todo.

A outra corrente do bem-estar consiste na idéia do bem-estar psicológico, inspirada na concepção eudaimonica da felicidade. Paschoal e Tamayo (2008) relatam que, para Aristóteles, o objetivo supremo de todo comportamento é a felicidade ou eudaimonia. A corrente do bem-estar psicológico acredita que os fatores fundamentais para a definição do construto foram desprezados pelos estudiosos da corrente hedônica. Dessa maneira, com o intuito de não se limitarem à visão hedônica e também de não confundirem o construto com seus antecedentes, os autores dessa corrente sugeriram que o bem-estar fosse considerado não 
somente como prevalência de afeto positivo e satisfação com a vida, mas também abarcando a idéia de vitalidade e saúde mental.

Na opinião de Daniels (2000), os pesquisadores que adotaram a abordagem do bem-estar psicológico no contexto do trabalho definem e operacionalizam o bem-estar laboral de modo a misturar o bem-estar em si com seus possíveis antecedentes cognitivos. A alternativa proposta pelo autor é considerar apenas aquele que tem se mostrado o aspecto mais relevante e central do bem-estar, ou seja, o afeto. Esse autor, afirma que o bem-estar afetivo se perfaz em uma experiência cumulativa de afetos, relativa a domínios específicos da vida e, por causa disso, poderia ser considerada em relação ao trabalho. Ratificando essa posição, Paschoal e Tamayo (2008) sustentam que os afetos nesta proposta correspondem às emoções e humores vivenciados pelo trabalhador. Afeto na literatura organizacional muitas vezes se relaciona com outros dois construtos, como humor e emoções. Para os autores, o humor no trabalho tem sido concebido como estados emocionais dificilmente identificados com um estímulo particular e que apresentam maior duração e consistência que emoções específicas. Já as emoções costumam ser tratadas como intensas, associadas a estímulos específicos, além de serem descritas sob forma discreta, como por exemplo, raiva e medo.

No âmbito nacional, Paz (2004) apresenta uma proposta para o construto mais voltada para o contexto organizacional, considerando aspectos situacionais que seriam indissociáveis do construto. A autora trabalha com dois pontos principais: gratificação e desgosto. $\mathrm{O}$ primeiro contempla a percepção do colaborador a respeito da valorização do trabalho, reconhecimento pessoal, autonomia, expectativa de crescimento, suporte ambiental, recursos financeiros e orgulho de pertencer à organização. $\mathrm{O}$ segundo seria o reflexo do mal-estar do colaborador, consistindo basicamente na oposição da gratificação.

Porto e Tamayo (2003), em consonância com Paz (2004), já haviam ressaltado que o trabalho contribui para auto-estima, saúde mental e convívio social. Nesse sentido, Tamayo (2004) vislumbra no tempo dedicado ao trabalho um componente fundamental para se construir e desenvolver o bem-estar pessoal e a própria felicidade. Dessa forma, o trabalho atende ao desejo humano pela busca do bem-estar a partir do momento em que o colaborador se vê na condição de um membro produtivo da sociedade e cumprindo seu objetivo de vida.

Os estudos publicados nos últimos cinco anos foram elaborados, em sua totalidade, no contexto do setor público, o que sinaliza a necessidade de se realizar pesquisas no setor privado e no terceiro setor, com realidades distintas e cujos resultados podem delinear novas 
Comprometimento, bem-estar e satisfação dos professores de administração de uma universidade federal

perspectivas de investigação. A grande maioria dos artigos foi de natureza quantitativa, ora validando escalas (PASCHOAL e TAMAYO, 2008), ora adaptando escalas para a realidade brasileira (GOUVEIA e outros, 2008) e ora conduzindo estudos relacionais (GOMIDE JÚNIOR e HERNANDEZ, 2005; PAIVA e BORGES, 2009), onde foi mostrado que as condições de trabalho influenciam positivamente o bem-estar dos colaboradores e que este prediz fatores como produtividade, absenteísmo e rotatividade.

Houve um único ensaio teórico que buscou revisar os conceitos de bem-estar subjetivo e bem-estar psicológico, apresentando com mais ênfase a concepção do bem-estar no trabalho (SIQUEIRA e PADOVAM, 2008). As autoras enfatizam a importância da psicologia positiva para se atingir maiores níveis de bem-estar e prevenir patologias, destacando que o bem-estar no trabalho estão relacionados a uma série de fatores sociais e organizacionais como responsabilidade sócio-ambiental, adoção de práticas de governança corporativa e políticas em prol dos colaboradores.

Em tese, observa-se que a produção teórica e a pesquisa empírica concernente a esse construto ainda são escassas, uma vez que ainda há a busca de uma identidade conceitual do bem-estar. Grande parte dos estudos dedica-se a analisar o bem-estar geral, desvinculado de qualquer contexto, como ressaltado por Paschoal e Tamayo (2008) que optaram por vincular o construto ao trabalho. É essa proposta que foi adotada na presente pesquisa, considerando o construto bem-estar no trabalho composto por uma dimensão afetiva (emoções e humores no trabalho) e uma dimensão cognitiva (percepção de expressividade e realização pessoal no trabalho), contemplando pontos principais da abordagem hedônica e da abordagem eudaimonica.

\subsection{Satisfação no trabalho}

A satisfação no trabalho é uma variável importante para os estudos organizacionais. Staw e Ross (1985) ressaltam que esta é uma das variáveis mais comumente estudadas em Psicologia Organizacional. Já em 2006, Valle (2007) identificou 15.600 publicações, em língua portuguesa, entre artigos, dissertações, teses, apresentações em congressos, entre outros, relacionados direta ou indiretamente à satisfação no trabalho. Martinez (2002) explica que no século XX, o construto satisfação era relacionado ao processo motivacional, tendo, portanto, certa ligação com as teorias relacionadas ao comportamento no trabalho, como a teoria da

REAd I Porto Alegre - Edição 72 - N 2 - maio/agosto 2012 - p. 290-316 
hierarquia das necessidades de Maslow, de 1970, a teoria X e Y elaborada por McGregor em 1960 e a teoria dos dois fatores de Herzberg, Mausner e Snyderman, de 1959.

Sob esse prisma, Siqueira (1995) advoga que os administradores começaram a defender a satisfação como causa de comportamentos dos seus colaboradores no trabalho refletindo assim, no desempenho, produtividade, rotatividade e absenteísmo. Segundo a autora, da década de 1980 em diante, a satisfação passou a ser entendida como uma atitude, detentora de componentes afetivos e cognitivos, capaz de predizer diversos comportamentos no trabalho.

Apesar do empenho dos pesquisadores, não há consenso a respeito da definição e da natureza do construto satisfação no trabalho. Na visão de Marinho (1988), há uma tendência em caracterizar o construto de acordo com uma natureza afetiva, ainda que o próprio autor vislumbre um traço disposicional. Weiss (2002) conceituou o construto como um julgamento positivo ou negativo que um indivíduo possui sobre o seu trabalho ou determinada situação de trabalho. Hazan e Shaver (1990) ressaltam a relação entre o trabalho e os vínculos afetivos do colaborador. Valle (2007) afirma, também, que a maioria dos determinantes do construto (facetas) inclui sistemas de recompensas, fatores como distribuição e centralização de poder, diferenças individuais como auto-estima e a necessidade de realização.

Outros estudos investigaram a relação entre satisfação com variáveis relacionadas ao trabalho e ao colaborador. A relação entre satisfação no trabalho e rotatividade foi investigada por Hellman (1997) enquanto que Krausz, Kolowsky e Eiser (1998) pesquisaram a relação do construto com o absenteísmo e Butler e Ehrich (1991) relacionaram a satisfação no trabalho com o desempenho do colaborador na organização. Dessa forma, entende-se que a satisfação no trabalho já foi estudada tanto como uma variável preditora quanto critério em muitos estudos.

No século XXI, o construto satisfação é vislumbrado como um dos vários conceitos que trabalham com a afetividade no trabalho. Siqueira e outros (2008) determinam o enfoque do construto como sendo o resultado do ambiente organizacional sobre a saúde do colaborador. Para os autores, a satisfação pode ser apontada como um dos três componentes psicossociais do conceito de bem-estar no trabalho, juntamente com envolvimento com o trabalho e o comprometimento organizacional afetivo.

Siqueira e Gomide Júnior (2004) expõem que quanto à dimensionalidade, a satisfação pode ser considerada como um conjunto de reações específicas a vários componentes do trabalho, capazes de desencadear no indivíduo diferentes graus de satisfação/insatisfação 
Comprometimento, bem-estar e satisfação dos professores de administração de uma universidade federal

(visão multidimensional). Conforme essa visão, diferentes aspectos do trabalho são considerados como fontes de satisfação no trabalho, sendo os mais freqüentes os fatores chefia, colegas de trabalho, o próprio trabalho, salário e oportunidades de promoção. Enquanto chefia e colegas de trabalho constituem-se em dimensões relativas ao ambiente social, o próprio trabalho representa as atividades realizadas. Salário e oportunidades de promoção são, por sua vez, aspectos da gestão de pessoas por meio dos quais a organização manifesta sua retribuição ao empregado, constituindo-se em duas maneiras possíveis do empregado observar resultados de seus investimentos na organização e avaliar sua relação de troca com esta.

Consoante com esta proposta, a presente pesquisa utilizou a concepção de satisfação no trabalho como um atributo afetivo relativo ao grau de contentamento do colaborador frente ao seu trabalho, sendo, portanto, uma variável atitudinal com enfoque pós-cognitivo e caráter multidimensional. Dentro desse escopo, satisfação é “... um elo afetivo com o trabalho, que se desenvolve a partir de cognições elaboradas pelo empregado sobre sua relação de troca social com o sistema...” (SIQUEIRA, 1995, p.160). Ou, ainda, “... como um resultado (output) do ambiente organizacional sobre a saúde do trabalhador e é apontada como um dos três componentes psicossociais do conceito de bem-estar no trabalho, ao lado de envolvimento com o trabalho e comprometimento organizacional afetivo" (SIQUEIRA e outros, 2008, p. 266).

Em âmbito nacional, nos últimos cinco anos, o construto satisfação no trabalho foi relacionado a diferentes variáveis, quais sejam: comprometimento organizacional, estresse ocupacional, clima organizacional, desempenho, modernidade organizacional, absenteísmo e rotatividade (BERNSTORFF, 2007a, 2007b; BERNSTORFF e DAL ROSSO, 2008; CUNICO e ZAMPIER, 2008; CAMPOS e MALIK, 2008). No que diz respeito à satisfação no trabalho a partir de uma perspectiva multinível, Puente-Palacios e Borges-Andrade (2005) realizaram um estudo no qual se levantou a hipótese da participação de variáveis preditoras relativas tanto aos indivíduos quanto às equipes, concluindo que a satisfação não é explicada somente sob uma perspectiva, individual ou coletiva, e sim pela exploração do efeito conjunto de variáveis. Contributivas também foram as tentativas de validação e revalidação de escalas para mensuração da satisfação (SANT’ANNA, MORAES, KILIMNIK, 2005; COELHO JUNIOR e MOURA, 2008), não obstante, a mais utilizada no Brasil ainda é a versão reduzida da escala de Siqueira (1995).

REAd I Porto Alegre - Edição 72 - N 2 - maio/agosto 2012 - p. 290-316 
Em linhas gerais, a produção nacional recente a respeito da satisfação no trabalho focou diversos contextos organizacionais como instituições bancárias, empreendimentos comerciais, hospitais e órgãos públicos, prevalecendo, entretanto, as pesquisas conduzidas no setor público. Nesse sentido, são necessárias mais pesquisas no setor privado e, mesmo no terceiro setor, que possui dinâmica e pressupostos peculiares que podem levar a resultados interessantes e a novas linhas de investigação. A quase totalidade das pesquisas foi de natureza quantitativa, utilizando a regressão linear como principal técnica de análise de dados, o que delineia uma lacuna importante para estudos de abordagem híbrida (quali-quanti) e mesmo para abordagens e técnicas de análise mais sofisticadas como a multinível e a modelagem por equações estruturais.

\section{MÉTODO}

A presente seção está dividida em: modelo da pesquisa, caracterização do estudo e da amostra da pesquisa, os instrumentos de pesquisa utilizados e os procedimentos de coleta e análise estatística dos dados.

\subsection{Modelo da pesquisa}

O modelo da pesquisa mostrado na Figura 1 é composto por duas partes. Ambas possuem como variável independente o comprometimento organizacional que será mensurado suas três bases, afetiva, calculativa e normativa. A primeira parte possui como variável dependente o bem-estar no trabalho, mensurado nos fatores afetos positivos, afetos negativos e realização. A segunda parte possui como variável dependente a satisfação no trabalho que, por sua vez, será aferida pelos seus cinco fatores, a saber, chefia, natureza do trabalho, colegas, salário e promoções.

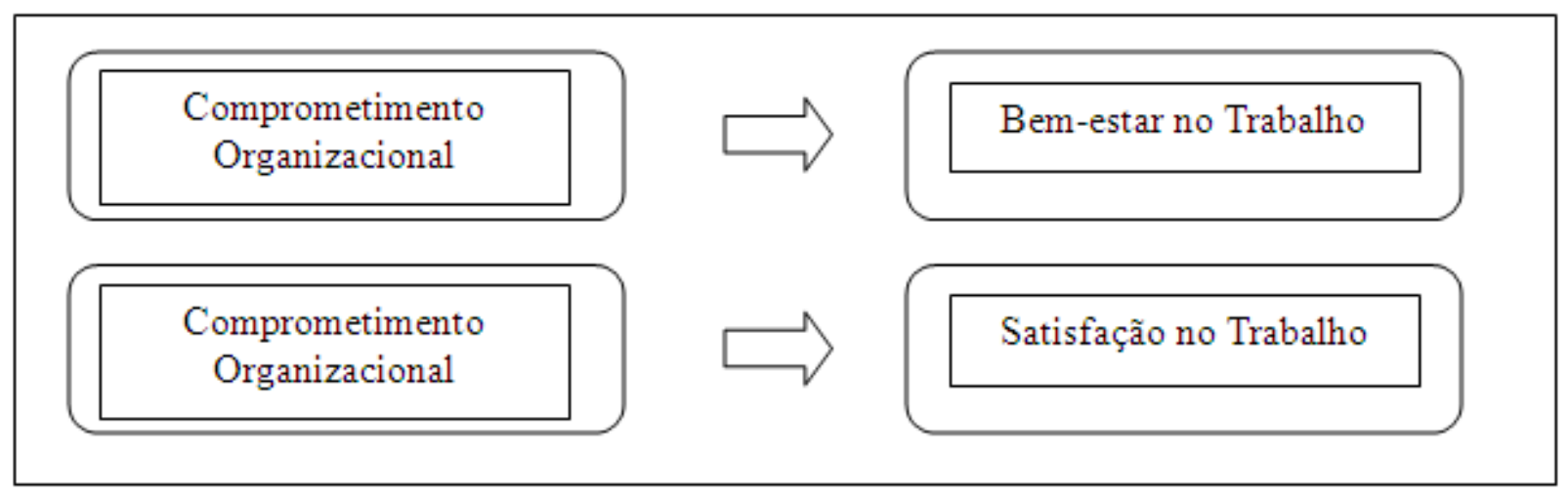

REAd I Porto Alegre - Edição 72 - N 2 - maio/agosto 2012 - p. 290-316 
Comprometimento, bem-estar e satisfação dos professores de administração de uma universidade federal

\section{Figura 1 - Modelo da pesquisa}

Fonte: autores

\subsection{Caracterização da pesquisa e da amostra}

Conforme Drenth (1984), o presente estudo pode ser caracterizado como explicativodescritivo, possuindo caráter transversal e natureza quantitativa. Foi realizado um censo (104 professores que lecionam disciplinas para alunos do curso de Administração) com taxa de resposta de $78 \%$ (81 professores). O cálculo para designar a quantidade mínima de participantes foi baseado em Tabachnick e Fidell (2001) que afirmam que o tamanho de uma amostra para procedimentos estatísticos como correlações e regressões múltiplas com mais de uma variável independente e uma variável dependente por meio da regra $\mathrm{N}=50+8 \mathrm{~m}$, onde $\mathrm{N}$ é o tamanho da amostra e m o número de variáveis independentes (VIs) do modelo. Nos dois sub-modelos desta pesquisa, elegeu-se uma variável independente (comprometimento organizacional) com três fatores (afetivo, calculativo e normativo), resultando em uma amostra mínima recomendada para regressão de 74 participantes.

Deve-se avaliar, ainda, a amostra mínima para obter poder estatístico. Segundo Cohen (1992), a análise do poder estatístico explora as relações entre as 3 variáveis envolvidas em inferência estatística, a saber, tamanho da amostra $(\mathrm{N})$, critério de significância $(\alpha)$, efeito do tamanho da população (ES) e o poder estatístico. Utilizando-se o programa "G Power”, versão 3.1, com $\alpha=0,05$, ES médio, poder estatístico de 0,80 (recomendados em estudos comportamentais) e número de variáveis independentes igual a três (três bases do comprometimento organizacional), obteve-se uma amostra mínima recomendada para o uso da regressão linear de, aproximadamente, 76 participantes.

\subsection{Instrumentos utilizados na pesquisa}

Quanto aos instrumentos de pesquisa, foram utilizadas as escalas de Siqueira $(1995,2000)$ para identificação do comprometimento afetivo, num total de 27 itens (ECOA - 5 itens, com um total de variância explicada de $68,2 \%$ e índice de confiabilidade de 0,93 ), calculativo (ECOC - 15 itens, com um total de variância explicada de 56,8\% e índice de confiabilidade de 0,92) e normativo (ECON - 7 itens, com um total de variância explicada de 50,87\% e índice de confiabilidade de 0,86 ). Tratam-se de escalas de cinco pontos variando de "nada" a 
"extremamente" para o comprometimento afetivo e de "discordo totalmente" a "concordo totalmente" para os comprometimentos calculativo e normativo.

Para avaliação do bem-estar no trabalho, foi adotada a escala de bem-estar no trabalho validada por Paschoal e Tamayo (2008). A escala é dividida em três fatores, quais sejam: emoções/humores positivos (9 itens), emoções/humores negativos (12 itens) e expressividade/realização no trabalho (9 itens), perfazendo um total de 30 itens. Os coeficientes de fidedignidade variaram de 0,88 a 0,93. O total da variância explicada corresponde a 57,30\%. Para os itens de afeto (positivo e negativo), foi utilizada uma escala de cinco pontos, variando do "nenhum pouco" ao "extremamente". Para os itens correspondentes à realização/expressividade, foi também usada uma escala de cinco pontos, variando do "discordo totalmente" ao "concordo totalmente".

Quanto à mensuração da satisfação no trabalho, foi adotada a versão reduzida da escala de Siqueira (1995), com 15 itens, distribuídos em 5 fatores, com um total de variância explicada de 64,80\% e índices de confiabilidade variando entre 0,77 e 0,90. Trata-se de uma escala de cinco pontos, variando de 1 (muito insatisfeito) a 5 (muito satisfeito).

\subsection{Procedimentos de coleta e análise dos dados}

A coleta de dados foi realizada via contato pessoal ou via correio eletrônico com cada professor, informando o objetivo da pesquisa, apresentando o questionário e seus critérios para preenchimento bem como o prazo para devolução do mesmo. A coleta foi concluída em 53 dias do segundo semestre de 2009.

Para analisar os dados, em primeira instância, foi feita uma análise descritiva simples para identificar o comprometimento organizacional, o bem-estar e a satisfação no trabalho dos professores. Em seguida, procedeu-se às análises exploratórias de limpeza e tratamento dos dados (para examinar questões como multicolinearidade e singularidade, normalidade, omissão de informações e presença de outliers - valores claramente afastados dos demais valores e da média - e análises de distribuição de frequiência para constatar sua coerência (média, desvios-padrão e valores máximo e mínimo dentro do esperado) que visam analisá-los e identificar o atendimento aos pressupostos das análises do modelo linear geral segundo orientações de Tabachnick e Fidell (2001). Após esta etapa, foram identificados e eliminados 5 outliers, aproveitando-se 76 questionários (ou $73 \%$ da população) para as análises, 
Comprometimento, bem-estar e satisfação dos professores de administração de uma universidade federal

quantidade ainda suficiente para o uso de regressão linear conforme Tabachnick e Fidell (2001) e Cohen (1992).

Foram efetuadas, então, para predição do bem-estar e da satisfação no trabalho, a partir do comprometimento organizacional, 8 regressões múltiplas, uma para cada fator do bemestar no trabalho (3 fatores) e da satisfação no trabalho (5 fatores). Tabachnick e Fidell (2001) definem a regressão múltipla como um conjunto de técnicas estatísticas que possibilita avaliar a relação entre VIs e VDs tendo como resultado final uma equação linear que representa a melhor predição de uma VD a partir de diversas VIs. Estas autoras ainda destacam que a qualidade do modelo de investigação adotado por um pesquisador pode ser avaliada, mormente, por meio do coeficiente de determinação $\mathrm{R}^{2}$, que indica a quantidade da variância das VDs (no caso, dimensões do bem-estar e da satisfação no trabalho) que é explicada conjuntamente pelas VIs propostas (no caso, comprometimento organizacional nas bases afetiva, calculativa e normativa), constituindo-se no parâmetro mais usado para interpretar os resultados de uma regressão linear.

\section{RESULTADOS E DISCUSSÃO}

O principal objetivo da pesquisa realizada foi avaliar a influência do comprometimento organizacional na satisfação no trabalho e no bem-estar no trabalho dos professores que lecionam disciplinas para alunos do curso de Administração na universidade pesquisada. Identificaram-se, também, os níveis de comprometimento, bem-estar e satisfação destes professores.

Quanto à percepção dos professores no que tange ao comprometimento organizacional, destacou-se a base afetiva, com média 3,79 em uma escala de 5 pontos. As médias das bases normativa e calculativa foram 2,82 e 2,80 , respectivamente. Considerando " 3 " como o ponto neutro que corresponde, no questionário, a "não concordo nem discordo" nas escalas de comprometimento organizacional calculativo e normativo, percebe-se que os professores não são comprometidos nessas bases. A Tabela 1 ilustra estes resultados.

Tabela 1 - Distribuição de Frequência do Comprometimento Organizacional

\begin{tabular}{cccccc}
\hline $\begin{array}{c}\text { Comprometimento } \\
\text { Organizacional }\end{array}$ & Média & Desvio Padrão & Variância & Máximo & Mínimo \\
\hline Afetivo & 3,79 & 0,8239 & 0,6788 & 5 & 1,40 \\
Normativo & 2,82 & 0,8286 & 0,6866 & 4,71 & 1 \\
Calculativo & 2,80 & 0,7897 & 0,6237 & 4,33 & 1,33 \\
\hline
\end{tabular}

REAd I Porto Alegre - Edição 72 - N 2 - maio/agosto 2012 - p. 290-316 
Fonte: autores

A partir desses resultados, pode-se inferir que os professores se mantêm na universidade pesquisada porque realmente gostam e acreditam na instituição e não por se sentirem obrigados ou atrelados apenas aos ganhos proporcionados, até porque os salários não são dos mais atrativos nessa profissão. Nesse sentido, é interessante notar que, nesta pesquisa, identificaram-se, no Departamento de Administração no período da pesquisa, 7 professores (cerca de $14 \%$ do total de professores do referido departamento) que possuíam um vínculo de colaborador com a universidade estudada, sem receber qualquer remuneração, mas simplesmente para terem uma oportunidade de trabalhar no que gostam, para ganhar experiência, rede de relacionamentos e status no curriculum vitae. Segundo os docentes, ser professor da universidade pesquisada dá prestígio.

Em seguida, destacaram-se as dimensões realização (média 4,05) e afetos positivos (média 3,71) referentes ao bem-estar no trabalho. Os afetos negativos foram pouco representados, com uma média de 1,71. A Tabela 2 apresenta estes resultados.

Tabela 2 - Distribuição de Frequência do Bem-Estar no Trabalho

\begin{tabular}{cccccc}
\hline Bem-Estar no Trabalho & Média & Desvio Padrão & Variância & Máximo & Mínimo \\
\hline Realização & 4,05 & 0,6615 & 0,4377 & 5 & 2,44 \\
Afetos Positivos & 3,75 & 0,6974 & 0,4863 & 5 & 1,56 \\
Afetos Negativos & 1,71 & 0,6365 & 0,4052 & 4,33 & 1 \\
\hline
\end{tabular}

Fonte: autores

Percebe-se que os professores apresentaram bons níveis de realização no trabalho e afetos positivos prevalentes em relação aos afetos negativos. Parece que trabalhar na universidade em questão contribui para os planos e metas que os professores traçaram para as suas vidas e, ainda, que o trabalho proporciona experiências positivas uma vez que está presente a percepção de humores positivos na instituição como alegria, disposição, contentamento, entusiasmo e outros estados favoráveis. Isso talvez possa ser explicado pelo fato de que a maioria dos professores trabalha na universidade por prazer, porque gostam do que fazem, por reconhecimento e mesmo em função do status proporcionado. O grande vínculo deve ser afetivo mesmo.

REAd I Porto Alegre - Edição 72 - N 2 - maio/agosto 2012 - p. 290-316 
Comprometimento, bem-estar e satisfação dos professores de administração de uma universidade federal

E, por fim, os professores declararam-se satisfeitos no trabalho quanto à chefia (média 4,23), aos colegas (média 4,02) e à natureza do trabalho (média 3,42), composta por atividades de ensino, pesquisa e extensão. A Tabela 3 mostra estes resultados.

Tabela 3 - Distribuição de Frequência da Satisfação no Trabalho

\begin{tabular}{cccccc}
\hline $\begin{array}{c}\text { Satisfação } \\
\text { no Trabalho }\end{array}$ & Média & Desvio Padrão & Variância & Máximo & Mínimo \\
\hline Chefia & 4,23 & 0,6648 & 0,4420 & 5 & 2,33 \\
Natureza do Trabalho & 4,02 & 0,6086 & 0,3704 & 5 & 2 \\
Colegas & 3,42 & 0,7095 & 0,5035 & 5 & 1,33 \\
Promoçães & 2,85 & 0,8726 & 0,7614 & 4,67 & 1 \\
Salário & 2,67 & 0,9550 & 0,9121 & 4,33 & 1 \\
\hline
\end{tabular}

Fonte: autores

Este é um bom resultado, especialmente para o Departamento de Administração que concentra grande parte dos professores que lecionam disciplinas para alunos do curso de Administração. Isso pode talvez ser explicado pela nova gestão do departamento que tem engendrado esforços para melhorar o ambiente, os incentivos, as condições e o clima de trabalho, inclusive incentivando pesquisas como esta. A Tabela 4 sumariza os principais resultados das oito regressões realizadas.

Tabela 4 - Principais Resultados das Regressões

\begin{tabular}{|c|c|c|c|}
\hline Variável Dependente & Preditores & $\begin{array}{c}\text { Coeficiente de } \\
\text { Correlação } \\
\text { Padronizado }(\beta) \\
\end{array}$ & $\begin{array}{c}\text { Coeficiente de } \\
\text { Determinação } \\
\left(\mathbf{R}^{2}\right)\end{array}$ \\
\hline $\begin{array}{c}\text { Afetos Positivos } \\
\text { (Bem-Estar) }\end{array}$ & $\begin{array}{c}\text { Comprometimento } \\
\text { Organizacional Afetivo } \\
\end{array}$ & $0,531^{*}$ & $\mathbf{R}^{2}=0,281$ ou $28,1 \%$ \\
\hline $\begin{array}{c}\text { Afetos Negativos } \\
\text { (Bem-Estar) }\end{array}$ & $\begin{array}{c}\text { Comprometimento } \\
\text { Organizacional Afetivo }\end{array}$ & $-0,246^{*}$ & $\mathbf{R}^{2}=0,061$ ou $6,1 \%$ \\
\hline $\begin{array}{l}\text { Realização } \\
\text { (Bem-Estar) }\end{array}$ & $\begin{array}{c}\text { Comprometimento } \\
\text { Organizacional Afetivo }\end{array}$ & $0,438^{*}$ & $\mathbf{R}^{2}=0,233$ ou $23,3 \%$ \\
\hline \multirow{2}{*}{$\begin{array}{l}\text { Satisfação com o } \\
\text { Salário }\end{array}$} & $\begin{array}{c}\text { Comprometimento } \\
\text { Organizacional Normativo }\end{array}$ & $0,263^{*}$ & \multirow{2}{*}{$\mathbf{R}^{2}=0,210$ ou $21 \%$} \\
\hline & $\begin{array}{c}\text { Comprometimento } \\
\text { Organizacional Calculativo }\end{array}$ & $0,261^{*}$ & \\
\hline $\begin{array}{c}\text { Satisfação com os } \\
\text { Colegas }\end{array}$ & $\begin{array}{c}\text { Comprometimento } \\
\text { Organizacional Afetivo }\end{array}$ & $0,386^{*}$ & $\mathbf{R}^{2}=0,149$ ou $14,9 \%$ \\
\hline \multirow{2}{*}{$\begin{array}{c}\text { Satisfação com a } \\
\text { Chefia }\end{array}$} & $\begin{array}{c}\text { Comprometimento } \\
\text { Organizacional Afetivo }\end{array}$ & $0,431^{*}$ & \multirow[t]{2}{*}{$\mathbf{R}^{2}=0,288$ ou $28,8 \%$} \\
\hline & $\begin{array}{c}\text { Comprometimento } \\
\text { Organizacional Calculativo }\end{array}$ & $0,240^{*}$ & \\
\hline \multirow{2}{*}{$\begin{array}{l}\text { Satisfação com as } \\
\text { Promoç̃̃es }\end{array}$} & $\begin{array}{c}\text { Comprometimento } \\
\text { Organizacional Afetivo }\end{array}$ & $0,328^{*}$ & \multirow[t]{2}{*}{$\mathbf{R}^{2}=0,234$ ou $23,4 \%$} \\
\hline & Comprometimento & $0,278^{*}$ & \\
\hline
\end{tabular}

REAd I Porto Alegre - Edição 72 - N 2 - maio/agosto 2012 - p. 290-316 


\begin{tabular}{cccc}
\hline \multicolumn{3}{c}{ Organizacional Calculativo } \\
\hline $\begin{array}{c}\text { Satisfação com } \boldsymbol{a} \\
\text { Natureza do Trabalho }\end{array}$ & $\begin{array}{c}\text { Comprometimento } \\
\text { Organizacional Afetivo }\end{array}$ & $0,387^{*}$ & $\mathbf{R}^{2}=0,149$ ou $14,9 \%$ \\
\hline Notal &
\end{tabular}

Nota. O coeficiente de correlação padronizado, o parâmetro $\beta$, na equação de regressão múltipla, representa a magnitude e a direção do relacionamento entre cada um dos preditores e a variável dependente; o coeficiente de determinação $\mathrm{R}^{2}$ representa a quantidade da variância da variável dependente explicada em conjunto pelas variáveis independentes.

Fonte: Dados da pesquisa.

*valores significativos $\mathrm{p}<0,05$.

Fonte: autores

Observou-se que para as variáveis bem-estar no trabalho e satisfação no trabalho, apareceu como principal preditor o comprometimento organizacional na base afetiva, significando que quanto mais o professor possui compromisso afetivo, maior é a percepção de humores positivos no ambiente de trabalho. $\mathrm{O}$ comprometimento organizacional afetivo foi o principal preditor das dimensões afetos positivos, afetos negativos (com relação negativa, ratificando a predição de afetos positivos) e realização do bem-estar no trabalho. $\mathrm{O}$ comprometimento organizacional afetivo foi também o principal preditor da satisfação com os colegas, da satisfação com a natureza do trabalho, da satisfação com a chefia e da satisfação com as promoções. Em suma, o professor que mantém o vínculo com a instituição por, principalmente, gostar e se identificar com ela, tenderá a ostentar maiores níveis de humores positivos, realização e satisfação em várias dimensões.

O comprometimento organizacional normativo foi o único que contribuiu para a explicação da satisfação com o salário. Pode-se conjeturar que uma vez que a remuneração faz parte do edital, já é conhecida e não é, segundo os próprios professores, um grande atrativo do concurso para universidades públicas, como a universidade em questão, o salário não geraria, por si só, um vínculo calculativo, tampouco afetivo. Assim, a satisfação com o salário derivaria do conhecimento e aceitação das normas, regras e valores da instituição, como o caso da remuneração e progressão funcional, que já são estabelecidas nos editais e demais documentos institucionais. Cabe ressaltar que a predição existe, embora tímida, ou seja, a satisfação com o salário é influenciada pelo comprometimento normativo, o que não significa dizer que os professores estão satisfeitos com os salários, como já colocado.

O comprometimento organizacional calculativo contribuiu para a explicação dos fatores satisfação com a chefia e satisfação com as promoções. Naturalmente, as recompensas recebidas pelos professores devem despertar-lhes satisfação com a chefia, autora dos benefícios concedidos, e satisfação com o reconhecimento, os incentivos recebidos e progressões alcançadas, que compõem, por sua vez, as recompensas financeiras e REAd I Porto Alegre - Edição 72 - N 2 - maio/agosto 2012 - p. 290-316 
Comprometimento, bem-estar e satisfação dos professores de administração de uma universidade federal

psicológicas, cerne do comprometimento calculativo. Em suma, os professores que se mantém na instituição por sentimento de obrigação ou aceitação (normativo) ou por vislumbrar uma vantagem em relação a outras oportunidades (calculativo), mostraram-se mais satisfeitos com o salário. A Figura 2 ilustra os preditores de cada dimensão ou fator do bem-estar e da satisfação no trabalho.

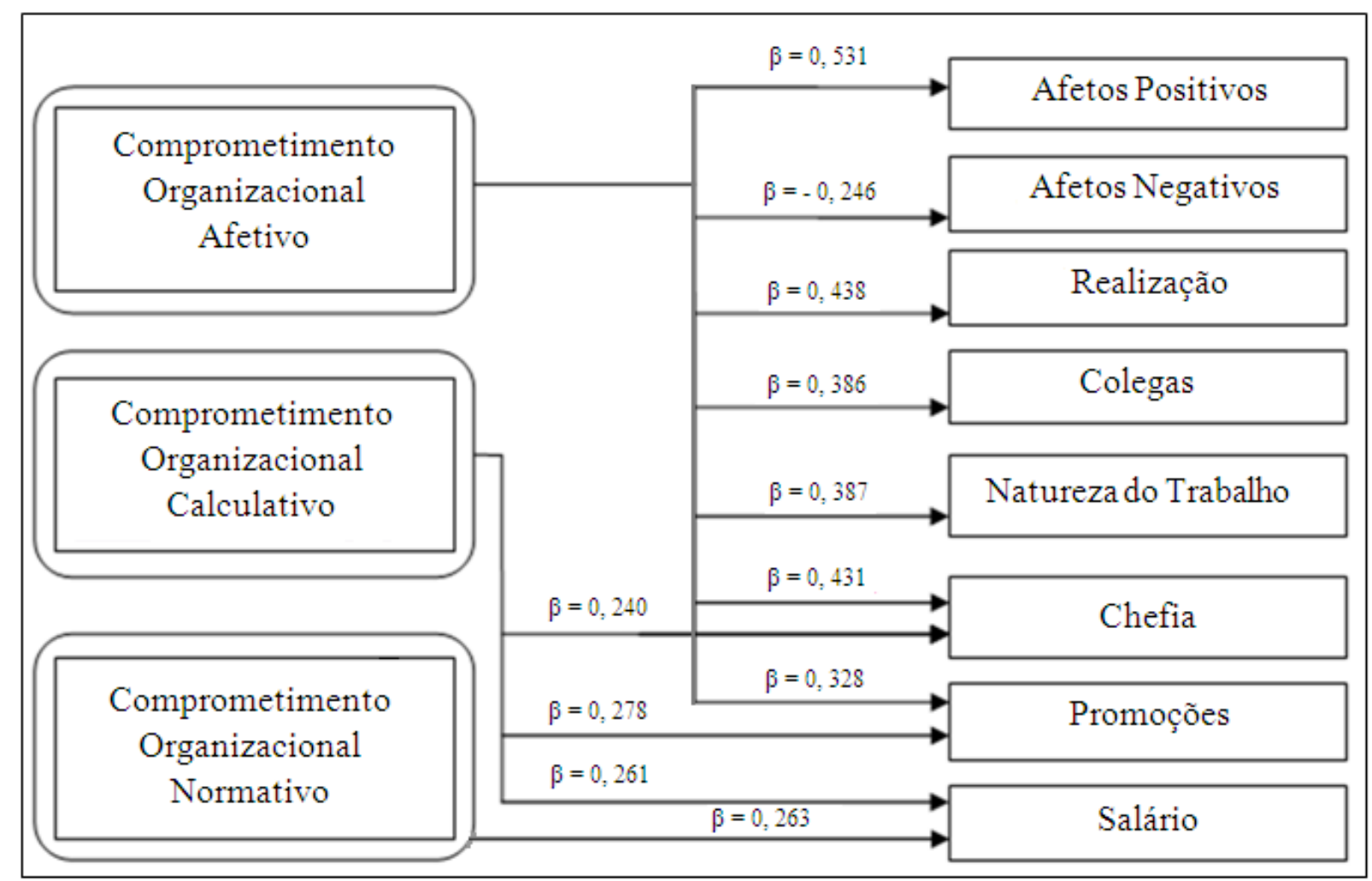

Figura 2 - Preditores do Bem-Estar e da Satisfação no Trabalho

Fonte: autores

Sabe-se que, atualmente, a qualidade na educação universitária preenche um considerável espaço entre as preocupações dos pesquisadores e dos gestores das instituições de ensino superior (ELLINGTON e ROSS, 1994; ROWLEY, 1996; HORSBURGH, 1999; MONTANO e UTTER, 1999). Souza, Mendonça e Zanini (2009) argumentam que as transformações ocorridas no mundo do trabalho, especialmente no que tange aos professores universitários, originam-se de questões como as determinações do Ministério da Educação e das agências de fomento a pesquisa e ensino (CAPES e CNPq), o crescente número de universidades que surgem nos grandes centros, o aumento das exigências em relação ao aprimoramento intelectual, à qualidade de trabalho e ao maior comprometimento desse profissional com a 
organização no sentido de atender essas múltiplas demandas aliadas a necessidade de formação do corpo discente com qualidade.

Todo esse processo afeta cada vez mais o docente e, destarte, torna-se imperativo engendrar pesquisas no afã de explicar as razões pelas quais os professores se sentem comprometidos ou não com as suas universidades. Na medida em que os gestores das universidades aprofundarem o conhecimento dessas razões, eles, a priori, estarão mais habilitados a fomentar o tão almejado comprometimento dos seus professores.

\section{CONSIDERAÇÕES FINAIS}

Os objetivos da pesquisa foram alcançados, uma vez que foram identificados os níveis de comprometimento, bem-estar e satisfação no trabalho da população pesquisada, bem como a relação entre estes construtos. O comprometimento organizacional, especialmente na base afetiva, de fato influenciou o bem-estar e a satisfação no trabalho.

Os resultados obtidos suscitam reflexões que subsidiam recomendações para estudos futuros, ou uma agenda de pesquisa. Como o estudo foi realizado em um momento único da realidade (caráter transversal), constituindo uma limitação do trabalho, recomenda-se a realização de estudos longitudinais que reavaliem as variáveis pesquisadas após a adoção de medidas a partir destes resultados desta. Da mesma forma, outra limitação do trabalho referese à quantidade de participantes do estudo. Apesar de ter sido realizado um censo, a quantidade de participantes, após a etapa de limpeza e tratamento dos dados, foi a mínima exigida para realização das regressões lineares.

Assim, expandir a pesquisa para outros cursos e, se possível, para a universidade pesquisada como um todo, na auspiciosa intenção de a universidade planejar uma agenda com fins de melhoria nas condições, atitudes e comportamentos de seus professores no trabalho. Também são bem-vindos trabalhos que busquem validar esta proposta em organizações privadas e não governamentais de diversos setores de atuação, realidades diferentes do setor de educação pública, com o objetivo de incrementar a generalidade dos resultados obtidos.

Primordial se faz, ainda, a realização de mais pesquisas sobre o bem-estar no trabalho. A produção, especialmente a nacional, carece de trabalhos a respeito desse assunto na área de Administração. A área de Psicologia domina as investigações relativas ao tema, mas ainda de maneira incipiente para a construção de um arcabouço teórico consistente.

REAd I Porto Alegre - Edição 72 - N 2 - maio/agosto 2012 - p. 290-316 
Comprometimento, bem-estar e satisfação dos professores de administração de uma universidade federal

Também seria salutar acrescentar outras variáveis que possam melhorar a qualidade e o poder de predição do modelo proposto como, por exemplo, a percepção de políticas de gestão de pessoas, de justiça organizacional e o compartilhamento (fit) dos valores pessoais e organizacionais. Ademais, ressalta-se que estudos qualitativos devem ser mais explorados com o objetivo de obter melhor e mais ampla compreensão dos construtos em estudo.

As recomendações por ora traçadas não são conclusivas, apenas se traduzem em convites para mais estudos que corroborem para um maior comprometimento, bem-estar e satisfação das pessoas nas organizações, bem como para o alcance de resultados organizacionais mais efetivos.

A pesquisa por ora realizada contribuiu para o avanço de estudos relacionados ao comprometimento organizacional, bem-estar no trabalho e satisfação no trabalho, um conjunto de variáveis ainda não explorado, e para melhor compreender e associar tais variáveis, subsidiando os gestores em seu planejamento e tomada de decisões. Os resultados obtidos corroboram a interdependência entre comprometimento, satisfação e bem-estar no trabalho, conforme sugerido por Siqueira (2008), além de confirmar a influência do comprometimento sobre a satisfação no trabalho constatada em estudos anteriores como o de Meyer (1997), Cohen (2000) e Rego (2002). A presente pesquisa ainda contribui com o conhecimento atual sobre Comportamento Organizacional e inova ao estudar e constatar a relação entre comprometimento organizacional e bem-estar no trabalho.

Especificamente quanto à satisfação e ao comprometimento em Instituições de Ensino Superior (IES) brasileiras e suas relações com cultura organizacional, diversos estudos foram conduzidos (DELA COLETA, MONTALVO e DELA COLETA, 2004; DELA COLETA, J. A. e DELA COLETA, M. F., 2005, 2007). Os autores mostraram que os professores tendiam a sentir-se mais satisfeitos e comprometidos com a instituição em que trabalhavam quando ela apresentava altos níveis de orientação para a afiliação, realização, futuro, assertividade, controle de incerteza e coletivismo e baixos índices de masculinidade e de distância hierárquica, características culturais estas que, por sua vez, caracterizam grande parte das IES brasileiras.

Na mesma linha, Dela Coleta e Mellão (2002) recolheram dados com 143 professores universitários de IES pública e privada, referentes a variáveis contidas nos modelos de cultura maior (social) e cultura menor (industrial) e a medidas de comprometimento organizacional e satisfação no trabalho. Os dados mostraram que quando foram consideradas as variáveis 
positivas do modelo de cultura menor (excelência, auto-estima, assertividade, internalidade, esperança ativa, otimismo e fortaleza) e as variáveis de satisfação no trabalho, constatou-se uma predominância de coeficientes de correlação positivos entre elas, demonstrando que maior aderência ao modelo de cultura menor, por parte dos professores universitários, representa maior tendência de satisfação no trabalho, ocorrendo exatamente o contrário quando foram consideradas as variáveis negativas, indesejáveis, predominantes no modelo de cultura maior. Quanto ao comprometimento organizacional, quase não aparecem correlações significativas com as variáveis motivacionais, exceção aos escores do enfoque instrumental, que apresentaram correlações negativas com os escores nas variáveis desejáveis do modelo de cultura menor.

Em síntese, o comprometimento organizacional influencia tanto o bem-estar quanto a satisfação no trabalho, devendo ser considerado nas tomadas de decisão quanto a políticas de gestão. Neste sentido, os gestores universitários devem dar especial atenção ao compromisso afetivo de seus professores, uma vez que este influencia todas as dimensões de bem-estar no trabalho, além da maioria dos fatores da satisfação no trabalho.

\section{REFERÊNCIAS}

ALBUQUERQUE, A. S.; TRÓCCOLI, B. T. Desenvolvimento de uma escala de bem-estar subjetivo. Psicologia: Teoria e Pesquisa, Brasília, v. 20, n. 2, 2004.

ALLEN, N. J.; MEYER, J. P. The measurement and antecedents of affective, continuance and normative commitment to the organization. Journal of Occupational Psychology, Leicester, v. 63, n. 2, p.1-18, 1990.

BASTOS, A. V. B. Comprometimento no trabalho: contextos em mudança e os rumos da pesquisa neste domínio. In: XXII Encontro da ANPAD (EnANPAD), 1998, Foz do Iguaçu. Anais...Foz do Iguaçu: XXII EnANPAD, 1998.

BERNSTORFF, V. H. A intensificação do trabalho, a satisfação profissional e seus efeitos sobre o estresse ocupacional. In: XXXI Encontro da ANPAD (EnANPAD), 2007, Rio de Janeiro. Anais...Rio de Janeiro: XXXI EnANPAD, 2007a.

; A satisfação profissional e as influências da organização do trabalho. In: XXXI Encontro da ANPAD (EnANPAD), 2007, Rio de Janeiro. Anais...Rio de Janeiro: XXXI EnANPAD, 2007b.

REAd I Porto Alegre - Edição 72 - N 2 - maio/agosto 2012 - p. 290-316 
Comprometimento, bem-estar e satisfação dos professores de administração de uma universidade federal

; DAL ROSSO, S. O absenteísmo ao trabalho como forma de resistência individual à intensificação do trabalho, à insatisfação profissional e ao estresse ocupacional. In: XXXII Encontro da ANPAD (EnANPAD), 2008, Rio de Janeiro. Anais...Rio de Janeiro: XXXI EnANPAD, 2008.

BUTLER, M. C.; EHRICH, E. J. Positional influences on job satisfaction and job performance: A multivariate predictive approach. Psychological Reports, Missoula, v. 69, n. 1, p.855-865, 1991.

CAMPOS, C. V. A.; MALIK, A. M. Satisfação no trabalho e rotatividade dos médicos do Programa de Saúde da Família. Revista de Administração Pública, Rio de Janeiro, v. 42, n. 2, p.347-368, 2008.

COELHO JUNIOR, F. A.; MOURA, C. F. Re-validação de escala de satisfação no trabalho. In: XXXII Encontro da ANPAD (EnANPAD), 2008, Rio de Janeiro. Anais...Rio de Janeiro: XXXII EnANPAD, 2008.

COHEN, A. The relationship between commitment forms and work outcomes: a comparison of three models. Human Relations, v. 53, n. 3, p. 387-417, 2000.

COHEN, J. A power primer. Psychological Bulletin, New York, v. 112, n. 1, p.155-159, 1992.

CUNICO, L. H.; ZAMPIER, M. A. Predição de satisfação de funcionários de uma rede de lojas do comércio varejista através da aplicação de técnicas em Data Mining. In: XXXII Encontro da ANPAD (EnANPAD), 2008, Rio de Janeiro. Anais...Rio de Janeiro: XXXII EnANPAD, 2008.

DANIELS, K. Measures of Five aspects of affective well-being at work. Human Relations, London, v. 53, n. 2, p.275-294, 2000.

DEMO, G. Comprometimento no trabalho: uma síntese do estado da arte e uma revisão da produção nacional. Revista Psicologia: Organizações e Trabalho, Florianópolis, v. 3, n. 2, p. 185-213, 2003.

DIENER, E. Subjective well-being: The science of happiness and a proposal for a national index. American Psychologist, Washington, v. 55, n. 1, p.34-43, 2000.

DELA COLETA, J. A.; MELLÃO, M. E. B. A motivação, o comprometimento e a satisfação no trabalho em grupos de professores universitários. Ícone - Educação, v.8, n.1/2, p. 93-106, 2002. 
DELA COLETA, J. A.; MONTALVO, J. J. M.; DELA COLETA, M. F. A cultura organizacional de instituições de educação superior, a satisfação e o comprometimento de seus professores. Ícone - Educação, v.10, n.1/2, p. 193-206, 2004.

DELA COLETA, J. A.; DELA COLETA, M. F. Escalas para medida da cultura organizacional de instituições de educação superior. Avaliação psicológica, v. 4, n.2, p. 155$164,2005$.

DELA COLETA, J. A.; DELA COLETA, M. F. Cultura organizacional e avaliação de instituições de educação superior: semelhanças e diferenças. PsicoUSF, v. 12, n.2, p. 227 237, 2007.

DRENTH, P. J. D. Research and work in organizational psychology: principles and methods. In: P. J. D. Drenth e outros. (Orgs.). Handbook of Work and Organization Psychology. 1984.

ELLINGTON, H.; ROSS, G. Evaluating teaching quality throughout a university. Quality Assurance in Education, v. 2, n. 2, p. 4-9, 1994.

GOLEMAN, D. Inteligência emocional. 5. ed. São Paulo: Objetiva, 1996.

GOMIDE JÚNIOR, S.; HERNANDEZ, J. D. Bem-estar no trabalho: os estudos realizados na Universidade Federal de Uberlândia. Revista da Sociedade de Psicologia do Triângulo Mineiro, Uberlândia, v. 9, n. 1, p.24-36, 2005.

GOUVEIA, V. V. e outros. Escala de bem-estar afetivo no trabalho (Jaws): evidências de validade fatorial e consistência interna. Psicologia: Reflexão e Crítica, Porto Alegre, v. 21, n. 3, p.464-473, 2008.

HAZAN, C.; SHAVER, P. R. Love and work: an attachment theoretical perspective. Journal of Personality and Social Psychology, Washington, v. 59, n. 1, p.270-280, 1990.

HELLMAN, C. M. Job satisfaction and the intent to leave. Journal of Personality and Social Psychology, Washington, v. 137, n. 6, p.677-689, 1997.

HORSBURGH, M. Quality monitoring in higher education: the impact on student learning. Quality in Higher Education, v. 5, n. 1, p. 9-25, 1999.

JUNIOR, J. C.; SANTOS, S. B. S; SILVA, A. F.; CHANG, M. S.; NOGUEIRA, A. A. Variáveis antecedentes ao comprometimento organizacional afetivo e sua relação com o 
Comprometimento, bem-estar e satisfação dos professores de administração de uma universidade federal

desempenho: uma abordagem estratégica baseada no modelo Resource Bases View - RBV. In: XXXI Encontro da ANPAD (EnANPAD), 2007, Rio de Janeiro. Anais...Rio de Janeiro: XXXI EnANPAD, 2007.

KRAUSZ, M.; KOLOWSKY, M.; EISER, A. Distal and proximal influences on turnover intention and satisfaction: Support for a withdrawal progression theory. Journal of Vocational Behavior, Maryland Heights, v. 52, n. 1, p.59-71, 1998.

MACKENZIE, S. B.; PODSAKOFF, P. M.; AHEARNE, M. Some possible antecedents and consequences of in-role and extra-role salesperson performance. Journal of Marketing, $v$. 62, p. 87-98, July 1998.

MÄKIKANGAS, A.; KINNUNEM, U. Psychosocial work stressors and well-being: Selfesteem and optimism as moderators in a one-year longitudinal sample. Personality and Individual Differences, Maryland Heights, v. 35, n. 3, p.381-391, 2003.

MARINHO, M. S. C. Satisfação no trabalho: uma revisão conceitual para a análise empírica. Ciência e Cultura, São Paulo, v. 40, n. 3, p. 213-222, 1988.

MARTINEZ, M. C. As relações entre a satisfação com aspectos psicossociais no trabalho e a saúde do trabalhador. 2002. 255 f. Dissertação (Mestrado em Saúde Ambiental) Faculdade de Saúde Pública da Universidade de São Paulo, São Paulo, 2002.

MEDEIROS, C. A. F. e outros. Comprometimento organizacional: o estado da arte da pesquisa no Brasil. Revista de Administração Contemporânea, São Paulo, v. 7, n. 4, p.187209, 2003.

MEYER, J. P. Organizational commitment. In: COOPER, C. L.; ROBERTSON, I. T. (Eds.). International review of industrial and organizational psychology. New York: John Wiley \& Sons, 1997. v. 12. p. 175-228.

; ALLEN, N. J., SMITH, C. A. Commitment to Organizations and occupations: extension and test of a three-component conceptualization. Journal of Applied Psychology, v.78, n.4, p.538-552, 1993.

MONTANO, C. B.; UTTER, G. H. Total quality management in higher education. Quality Progress, p. 52-59, Aug. 1999.

MOWDAY, R. T.; PORTER, R.W.; STEERS, R. M. Employee-organization linkages: the psychology of commitment, absenteeism and turnover. New York: Academic Press, 1982.

REAd I Porto Alegre - Edição 72 - N 2 - maio/agosto 2012 - p. 290-316 
PAIVA, C. S. D. L.; BORGES, L. O. O ambiente de trabalho no setor bancário e o bem-estar. Psicologia em Estudo, Maringá, v. 14, n. 1, p.57-66, 2009.

PASCHOAL, T.; TAMAYO, A. Construção e validação da escala de bem-estar no trabalho. Avaliação Psicológica, Porto Alegre, v. 7, n. 1, p.11-22, 2008.

PAZ, M. G. T. Poder e saúde organizacional. In: TAMAYO, A. (Org.). Cultura e saúde nas organizações. Porto Alegre: Artmed Bookman, 2004.

PORTO, J. B.; TAMAYO, A. Escala de valores do trabalho: EVT. Psicologia: Teoria e Pesquisa, Brasília, v. 19, n. 2, p.145-152, 2003.

PUENTE-PALACIOS, K. E.; BORGES-ANDRADE, J. E. O efeito da interdependência na satisfação de equipes de trabalho: um estudo multinível. Revista de Administração Contemporânea, Curitiba, v. 9, n. 3, p.57-78, 2005.

REGO, A. Comprometimento afectivo dos membros organizacionais: o papel das percepções de justiça. Revista de Administração Contemporânea, São Paulo, v. 6, n. 2, p.209-241, 2002 .

; CUNHA, M. P; SOUTO, S. Espiritualidade nas organizações e comprometimento organizacional. RAE-eletrônica, São Paulo, v. 6, n. 2, p.1-27, 2007.

RIBEIRO, J. A. Comprometimento organizacional e percepção de justiça: um estudo sobre a concessão de remuneração e benefícios diferenciados a dois grupos de uma mesma empresa. In: XXXII Encontro da ANPAD (EnANPAD),2008, Rio de Janeiro. Anais...Rio de Janeiro: XXXII EnANPAD, 2008.

ROWLEY, J. Measuring quality in higher education. Quality in Higher Education, v. 2, n. 3, p. 237-255, 1996.

SANT'ANNA, A. S.; MORAES, L. F. R.; KILIMNIK, Z. M. Competências individuais, modernidade organizacional e satisfação no trabalho: um estudo de diagnóstico comparativo. RAE - eletrônica, São Paulo, v. 4, n. 1, p.2-23, 2005.

SCHIRRMEISTER, R.; NUNES, L. A. P.; LIMONGI-FRANÇA, A. C.; GONÇALVES, A. F. As relações de trabalho no porto de Santos: um estudo sobre a qualidade de vida no trabalho e o comprometimento organizacional no contexto da modernização dos portos. In: XXXII Encontro da ANPAD (EnANPAD), 2008, Rio de Janeiro. Anais...Rio de Janeiro: XXXII EnANPAD, 2008. 
Comprometimento, bem-estar e satisfação dos professores de administração de uma universidade federal

SIQUEIRA, M. M. M. Antecedentes de comportamentos de cidadania organizacional: a análise de um modelo pós-cognitivo. 1995. 265 f. Tese (Doutorado em Psicologia) - Instituto de Psicologia da Universidade de Brasília, Brasília, 1995.

; Análises de três medidas de comprometimento organizacional: afetivo, calculativo e normativo. VIII Conferência Internacional de avaliação psicológica. Anais... Belo Horizonte, 2000.

; GOMIDE JÚNIOR, S. Vínculos do indivíduo com o trabalho e com a organização.

In: ZANELLI, J. C., BORGES-ANDRADE, J. E., BASTOS, A. V. B. (Org.). Psicologia, organizações e trabalho no Brasil. Porto Alegre: Artmed Bookman, 2004.

. (Org.) e outros. Medidas do comportamento organizacional: ferramentas de diagnóstico e de gestão. Porto Alegre: Artmed, p. 49-95, p. 265-275, 2008.

;PADOVAM, V. A. R. Bases teóricas de bem-estar subjetivo, bem-estar psicológico e bem-estar no trabalho. Psicologia: Teoria e Pesquisa, Brasília, v. 24, n. 2, p.201-209, 2008.

SOUZA, I. F.; MENDONÇA, H.; ZANINI, D. S. Burnout em docentes universitários. Revista Psicologia e Saúde, v. 1, n. 1, p.1-8, 2009.

STAW, B. M.; ROSS, J. Stability in the midst of change: A dispositional approach to job attitudes. Journal of Applied Psychology, Washington, v. 70, n. 1, p.469-480, 1985.

TAMAYO, A. (Org.). Cultura e saúde nas organizações. Porto Alegre: Artmed Bookman, 2004.

TABACHNICK, B.; FIDELL, L. S. Using multivariate statistics. 4. ed. San Francisco: Allyn e Bacon, 2001.

TENBRUNSEL, A. E. e outros. Handbook de Estudos Organizacionais. São Paulo: Atlas, 2002 .

VALLE, A. R. Monitoramento da satisfação no trabalho em uma empresa financeira. 2007. 180 f. Tese (Doutorado em Psicologia) - Instituto de Psicologia da Universidade de Brasília, Brasília, 2007.

WEISS, H. M. Desconstructing job satisfaction: Separations, beliefs and affective xperiences. Human Resource Management Review, Maryland Heights, v. 12, n. 2, p.173-194, 2002. 